\title{
Congestion Pricing Policies and Safety Implications: a Scoping Review
}

\author{
Bhavna Singichetti (D) Jamie L. Conklin • \\ Kristen Hassmiller Lich • Nasim S. Sabounchi • \\ Rebecca B. Naumann
}

Accepted: 24 September 2021 /Published online: 25 October 2021

(C) The New York Academy of Medicine 2021

\begin{abstract}
Congestion pricing policies (CPPs) are a common strategy for addressing urban traffic congestion. Research has explored several impacts of these policies (e.g., air quality, equity, congestion relief). The purpose of this review was to synthesize findings from publications examining CPP impacts on road user safety outcomes. We conducted a systematic
\end{abstract}

Supplementary Information The online version contains supplementary material available at https://doi. org/10.1007/s11524-021-00578-3.

B. Singichetti $(\bowtie) \cdot$ R. B. Naumann

Injury Prevention Research Center and Department of Epidemiology, University of North Carolina at Chapel Hill, 725 Martin Luther King Jr Blvd, CB \#7505, Chapel Hill, NC 27599, USA

e-mail: singichb@live.unc.edu

\section{J. L. Conklin}

Health Sciences Library, University of North Carolina at Chapel Hill, 335 S. Columbia St, CB \#75851, Chapel Hil, NC 27599, USA

K. Hassmiller Lich

Department of Health Policy and Management, University of North Carolina at Chapel Hill, 1105E McGavran-Greenberg Hall, CB \#7411, Chapel Hill, NC 27599, USA

\section{N. S. Sabounchi}

Department of Health Policy and Management, Center for Systems and Community Design, City University of New York, Graduate School of Public Health and Health Policy, 55 West 125th St, New York, NY 10027, USA search of relevant literature in four large research databases (Transport Research International Documentation, Web of Science, PubMed, and Scopus), searching from database inception through January 2021. We identified 18 eligible publications. Safetyrelated outcomes included overall crashes and injury crashes with stratification by injury severity and road user type (e.g., bicyclist, pedestrian). A majority of the publications examined zone-based CPPs $(n=13)$ and used observed data involving real policies $(n=10)$, as compared to a predicted or simulated analysis. Decreases in overall crashes and injuries for some road users were observed (e.g., car occupants). While some studies estimated short-term increases in injuries and crashes for bicyclists and motorcyclists (likely due to shifts from personal vehicle use to other transportation modes and increased exposure), most analyses focused on longer-term impacts and generally found a reversal and eventual decrease in injuries and crashes after a few years. The relative scarcity of safety outcomes in published literature, along with the wide breadth of CPP types, implementation contexts, and outcomes measured, demonstrates that more research on safety outcomes is needed. Cities and regions planning to implement CPPs should consider potential mode shifts and safety supports for all road users (e.g., bicycle and pedestrian infrastructure).

Keywords Congestion pricing policy $\cdot$ Road pricing $\cdot$ Traffic safety $\cdot$ Scoping review $\cdot$ Road traffic injury $\cdot$ Motor vehicle 


\section{Introduction}

Traffic congestion is a growing problem in the USA (US) and around the world, particularly in urban centers. In the USA alone, a total of 3,261,772 vehicle-miles were driven in 2019, compared to $2,691,335$ in 1999[1]. Congestion that is both affecting and affected by these travel trends is likely in part generated by land use patterns characterized by sprawl with expansion of urbanized areas, corresponding increases in distances between housing and other destinations, and travel routes where more and more people are forced to take longer trips on constrained road systems. These factors have resulted in negative impacts on travel time and air quality and present a significant burden on society. A survey of almost 500 USA urban areas showed that urban Americans spent an excess of 8.8 billion hours in travel time and an excess of 3.3 billion gallons of purchased fuel as a result of congestion in 2017 , amounting to $\$ 179$ billion in total congestion costs[2]. In 1982, however, total congestion costs equated to $\$ 15$ billion (in 2017 USD)—indicating that the burden of congestion in the USA has increased drastically in the last several years [2].

Congestion pricing has been explored as a way to reduce congestion and consequently reduce the aforementioned consequences, by using pricing strategies to change driving choices and behaviors to shift traffic towards less congested roadways, off-peak travel periods, to other transportation modes (e.g., transit, bicycle), or to eliminate trips altogether [3]. Congestion pricing policies (CPPs) have been implemented in cities and regions around the world, including London, Singapore, and Stockholm [3]. The structure of these policies varies. The US Federal Highway Administration groups CPPs into toll-based and non-toll-based policies. Toll-based policies include (1) variably priced lanes, (2) variable tolls on entire roadways, (3) zone-based or cordon charges, and (4) area-wide or system-wide charges [3, 4]. Non-toll-based policies include priced vehicle sharing, parking pricing, and mileage-based user fees [4]. This review focuses on toll-based policies, which are frequently researched, already exist in numerous cities and regions, and are currently being considered and/or are under development in cities such as New York City, Beijing, and San Francisco [5, 6].
There is a large body of original research, structured reviews, and other publications on CPPs including, but not limited to, simulation analyses of CPPs and their impacts on maximum traffic flow efficiency, impacts on congestion in specific cities/regions, driver choices/behaviors, air pollution/vehicle emissions, and public perceptions and acceptability [5, 7-15]; however, there appears to be relatively little research on potential safety impacts. If CPPs are successfully implemented, they can result in areas with less congested roadways, which may result in higher vehicle travel speeds-known to increase injury severity and risk of death when crashes happen [16]. Further, increased vehicle speed may inadvertently reduce vulnerable road user safety, and particularly pedestrian and bicyclist safety, travel modes that CPPs are often designed to increase.

Given the large and increasing burden of crashes, it is critical for transportation policy to center around safety. In 2019, there were an estimated 6,756,000 police-reported motor vehicle crashes across the USA, resulting in 36,096 fatalities and an estimated 2,740,000 injured people [17]. Road traffic crash fatality counts have increased by more than $10 \%$ over the last decade; and although this number decreased in 2020, the crash fatality rate (per 100 million vehicle miles traveled) has continued to increase since the start of the COVID-19 pandemic, despite fewer vehicle miles traveled [18-20]. Therefore, as cities consider such policies for reducing congestion, there is a need to understand the current state of the literature on road safety impacts overall and whether there are potential unintended consequences. As such, the purpose of this review was to systematically synthesize and summarize publications examining the association between toll-based CPPs and road user injury and safety outcomes.

\section{Methods}

Databases

We systematically searched the literature using a protocol consistent with Preferred Reporting Items for Systematic Reviews and Meta-Analysis (PRISMA) guidelines. A trained health sciences librarian and co-author on this study helped formulate the search strategy, which included the following four databases: 
Transport Research International Documentation (TRID), Web of Science, PubMed, and Scopus. Released in 2011, TRID is one of the most extensive bibliographic resources on transportation research, containing over 1.25 million research records from two databases: Transportation Research Board's (TRB) Transportation Research Information Services database and the Transport Research Centre's International Transport Research Documentation database. TRID, which is produced and maintained by TRB and sponsored primarily by state Departments of Transportation and the US Department of Transportation, is cross-disciplinary and includes US and international research, including peer reviewed publications and government research reports, on all modes of transportation. Web of Science, PubMed, and Scopus each access multiple peer-reviewed journals to create comprehensive databases of research and scholarly literature. Databases were searched from their dates of inception through January 24, 2021.

\section{Search terms}

To guide the publication search process, we relied on the definition of CPPs as described by the US Federal Highway Administration: Congestion pricing "is a way of harnessing the power of the market to reduce the waste associated with traffic congestion. Congestion pricing works by shifting purely discretionary rush hour highway travel to other transportation modes or to off-peak periods..." [3]. Specifically, we focused on four types of toll-based policies: variably priced lanes (e.g., toll lanes and high occupancy toll lanes), variable tolls on entire roadways (e.g., toll roads and bridges), zone- and cordon-based charges (variable or fixed fees to drive into or within a designated area, implemented on multiple roadways/entrypoints and usually for specific parts of a city), and area-wide or system-wide charges (per-mile charges on all roads within an area).

Search terms were compiled to align with the definitions above. The search strategy included combinations of terms related to (1) transportation, road,or traffic; (2) price(ing) or toll(s/ing) or charge(ing) or fee(s) or tax or policy; (3) congestion or area or zone(al) or distance or cordon or dynamic; and (4) safety, injury(ies), casualty(ies), death(s), and lives. The complete, reproducible search strategy with detailed search terms for all four databases is provided in the Appendix.

\section{Inclusion/exclusion criteria}

We included only peer-reviewed literature and published reports (e.g., government reports) and excluded other record types (i.e., news/media articles, commentaries, position papers, reviews/syntheses). No restrictions were placed on language of the publication; however, we required all documents to have an abstract or summary in English. We included publications that simulated or predicted CPP impacts, as well as evaluations of implemented policies. Additionally, only those publications that focused on policies which met the definition of a toll-based CPP and included discussion of safety outcomes were included. Publications that discussed policies that were implemented only for the purposes of generating revenue, but not to control traffic congestion, improve travel time, or reduce traffic, were excluded. Finally, this review focused specifically on roadway CPPs and, therefore, excluded CPPs involving air, train, or other non-roadway travel.

Screening strategy and data extraction

Publications identified using the search strategy presented above were input in Covidence (https:// www.covidence.org), an online screening and data extraction tool for streamlining the systematic review process. The first step was a title and abstract screening. Publications that remained after this step were then included in the full-text screening, which also included a review of references to identify any additional publications that may have been missed. Publications identified in this way were then screened (full-text) for inclusion in the review. For both screening steps (title/ abstract and full-text review), two members of the study team reviewed the publications independently within Covidence. The reviewers discussed any screening disagreements (identified by Covidence) and made final decisions together for exclusion or inclusion into the next step of the screening process. Finally, full-text publications were reviewed for final inclusion by both reviewers independently, again with agreement reached 
through discussion. A PRISMA diagram outlining this process is presented in Fig. 1. We thoroughly examined all publication meeting full eligibility criteria and extracted several key components, guided by a data extraction form designed by coauthors to align with the review purpose. Form elements included study/report purpose, policy(ies) examined, design/methods, data sources, location/ setting, time period, safety outcomes/measures, safety-specific results, other outcomes examined, assumptions, strengths, limitations, and key conclusions.

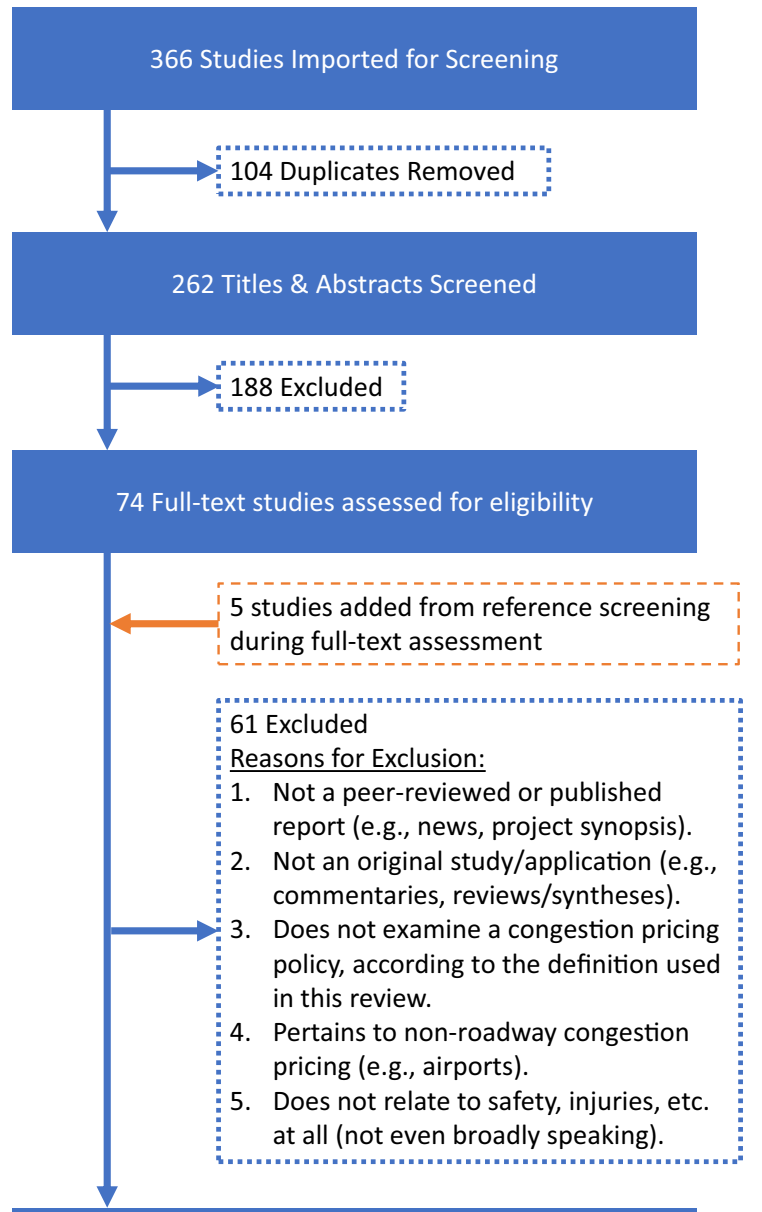

18 Final publications identified and included in completed extraction

Fig. 1 PRISMA Diagram* *Transport for London (TfL) Impact Monitoring Series counted as one publication in this diagram and in this review

\section{Results}

Through the multi-database search, we identified 366 publications (Fig. 1) for screening. We screened 262 titles and abstracts after removing 104 duplicates. One hundred eighty-eight were deemed irrelevant in this screening stage, leaving 74 publications for the full-text review. During review of these publications, 5 additional studies were added from references into the review. Of the 79 publications in the final full-text review, 18 publications were identified as eligible and included in the final extraction process [6, 21-42]. The impact monitoring series of six annual reports by Transport for London (TfL) is counted throughout as a single publication for the purposes of this review, as these reports incrementally built off of each other with each year adding additional data but maintaining similar methods and scope [32-37].

\section{General study characteristics}

For the 18 studies, publication years ranged from 1989 to 2021 (Table 1). Eight publications focused completely or partially on simulated data and/or projections under a hypothetical CPP, while the remaining evaluated existing policies and used observed data only $(n=10)$.

Settings included four in the USA, nine in the United Kingdom (UK), and five in other European countries. Eight of the nine UK publications examined London specifically. Thirteen of the 18 publications included safety as a primary focus of the analysis and article; however, all publications presented at least one finding related to safety (per eligibility criteria). Key policy attributes, types of study data, safetyrelated measures, and key findings by road user type are described in Table 1.

\section{Types of congestion pricing policies examined}

Identified publications examined three of the four types of pricing policies we searched for zone- and cordon-based, variable and static tolls on entire roadways, and area- and system-wide CPPs (Table 1). Zone- and cordon-based CPPs were described in 13 publications, and all included a time-varying (e.g., time of day, weekday vs weekend) component to the charges. Some policies also included exemptions for specific vehicle types, such as taxis, buses, and 
Table 1 General characteristics of safety-related congestion pricing policy publications $(n=18)$

\begin{tabular}{|c|c|}
\hline Characteristic & $N(\%)$ \\
\hline \multicolumn{2}{|l|}{ Year published } \\
\hline 2000 and earlier & $2(11.1)$ \\
\hline 2001-2010 & $6(33.3)$ \\
\hline 2011 and later & $10(55.6)$ \\
\hline \multicolumn{2}{|l|}{ Country } \\
\hline USA & $4(22.2)$ \\
\hline UK & $9(50.0)$ \\
\hline Other & $5(27.8)$ \\
\hline \multicolumn{2}{|l|}{ Publication type } \\
\hline Peer-reviewed journal article & $16(88.9)$ \\
\hline Government/technical report ${ }^{1}$ & $2(11.1)$ \\
\hline \multicolumn{2}{|l|}{ Policy type } \\
\hline Zone- and cordon-based & $13(72.2)$ \\
\hline Variable tolls on entire roadways & $3(16.7)$ \\
\hline Area- and system-wide & $2(11.1)$ \\
\hline Variably priced lanes & $0(0.0)$ \\
\hline \multicolumn{2}{|l|}{ Data type } \\
\hline Simulated data only & $6(33.3)$ \\
\hline Observed data only & $10(55.6)$ \\
\hline Simulated and observed data & $2(11.1)$ \\
\hline \multicolumn{2}{|l|}{ Safety as primary focus } \\
\hline Yes & $13(72.2)$ \\
\hline No & $5(27.8)$ \\
\hline \multicolumn{2}{|l|}{ Type of safety outcomes measured ${ }^{2}$} \\
\hline \multicolumn{2}{|l|}{ Direct measures } \\
\hline Crashes (injury and non-injury crashes) & $11(61.1)$ \\
\hline Any injury types (including overall "car casualties") ${ }^{3}$ & $10(55.6)$ \\
\hline Stratified injury severity categories ${ }^{4}$ & $6(33.3)$ \\
\hline \multicolumn{2}{|l|}{ Indirect measures } \\
\hline Economic valuations corresponding to at least one direct measure of safety & $4(22.2)$ \\
\hline Changes in quality-adjusted life years & $1(5.6)$ \\
\hline Vehicle-miles-travelled per work-person trip (for relative exposure and probability of crash) & $1(5.6)$ \\
\hline Congestion level (for relative crash severity and probability of crash occurrence) & $1(5.6)$ \\
\hline \multicolumn{2}{|l|}{ Specific vehicle/road user outcomes evaluated ${ }^{2}$} \\
\hline Bicyclists & $6(33.3)$ \\
\hline Motorcyclists (and other powered two-wheeled users) & $4(22.2)$ \\
\hline Pedestrian & $2(11.1)$ \\
\hline Taxis & $2(11.1)$ \\
\hline Buses, cargo trucks, and other heavy vehicles & $2(11.1)$ \\
\hline
\end{tabular}

${ }^{1}$ Transport for London (TfL) report series counted as 1 publication

${ }^{2}$ Not mutually exclusive

${ }^{3}$ Car casualties are defined as crashes with at least one injury of any severity

${ }^{4}$ This category is a subset of the "Any Injury Types" category. Detailed Injury Severity categories, where available, vary and include fatal/non-fatal and slightly injured/killed-or-seriously injured 
alternative-fuel vehicles, while one was combined with a network-wide toll proportional to travel time. Three publications described time-of-day variable tolls on specific roadways. Area-and system-wide charges, a less popular form of CPPs, were described in two publications. Although numerous studies of variably priced lanes were identified in the title/ abstract screening stage, none were identified as discussing the policy's safety impacts and, therefore, were not included in this review.

Observed vs simulated data

Broadly, two types of data were used in CPP research examining impacts on safety-related outcomes: (1) observed data following implementation of real policies and (2) simulated data for the purpose of predicting outcomes of currently implemented policies or for hypothetical policies that had not been implemented. Of the 18 publications examined, 10 used observed data only, six used simulated data only, and two used both observed and simulated data. Studies using simulated data use scientific evidence and/or expert opinion to develop and parameterize models, which were then used to project outcomes (including safety). For example, Yu et al. built their simulation model using pre-existing data, as well as rates and other model parameters from prior research, with the study purpose of comparing simulated outcomes under two different CPPs [6]. Studies using both observed and simulated data included comparison of observed pre-CPP data to simulated post-CPP data [21], and a combination of simulated predictions published pre-CPP and observed findings published post-CPP [32-37].

\section{Safety measures}

Types of measures used to assess CPP safety impacts varied considerably across the literature and are summarized in Table 1 . The most common safety impact measures were crashes $(n=11)$ and injury crashes/ car casualties ( $n=10$; "car casualty" defined as a crash including at least one vehicle and at least one injury of any severity). Six publications provided stratified results for injury crashes by injury severity (fatal/non-fatal and slightly injured/killed or seriously injured) [22, 23, 25, 29, 32-37, 42]. One study considered risks of fatal and non-fatal injury outcomes in their calculation of life expectancies and overall health benefits [6]. Other indirect measures of safety included additional calculations of the cost/economic valuations of the direct safety outcomes measured and efficiency (e.g., congestion level) of the roadway/ region to which the CPP applied. Measures also varied by type (counts, percent changes, and rates) and over different time intervals (monthly or annually).

\section{Key findings}

\section{Overall road traffic crashes and casualties}

Sixteen of the 18 publications reported findings or estimates of reduced traffic-related harms and increased safety benefits as a result of implementing a CPP for at least one measured safety outcome and/ or in at least one scenario/analysis (see Table 1 for list of measured safety outcomes; see Table 2 for findings of the 18 publications) [6, 21-30, 32-39, 41, 42]. Estimated reductions of the number of road traffic crashes following CPP implementation included 3.6\% per year in Stockholm's zone-based charging area and $35 \%$ per month in London's zone-based charging area [23, 27]. Further, an additional study of London's policy observed not only a $46.3 \%$ decrease in road traffic crashes in the charging zone but also observed significant decreases in non-charged areas adjacent to the charging zone [30]. Consistent with these studies, Balwani and Singh also projected decreases in crashes as a result of congestion charges using simulated data [41].

Changes in the number of fatalities varied even more dramatically across studies, anywhere from no observed changes in the three years following CPP implementation in Milan to decreases as high as $33 \%$ in the 2 years following implementation in London $[22,26]$. In London specifically, two studies of changes in car casualties in the first year post-implementation found $3.4 \%$ and $5.2 \%$ reductions (using Box and Tiao intervention and difference-in-difference approaches, respectively) [25, 28]. Other studies observed a $27 \%$ reduction over 2 years post-implementation (calculated per month) [26], and an overall $4.3 \%$ reduction over 4 years post-implementation [29]. Also in London, the fifth report of the TfL series, which compared numbers for measured outcomes from similar periods across multiple years (e.g., Mar 2003-Feb 2004 versus Mar 2004-Feb 2005), estimated that through three years post-implementation, traffic 


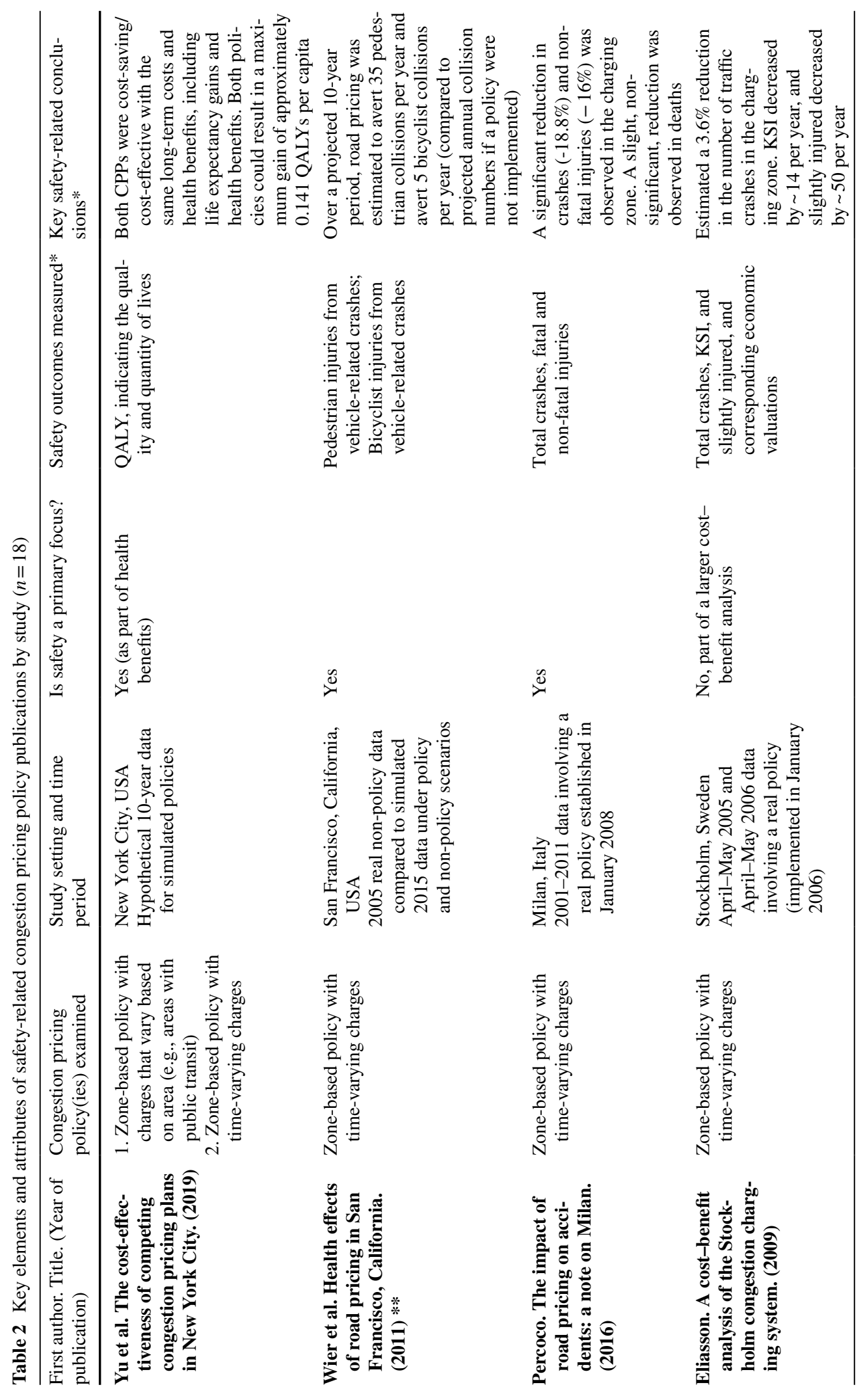




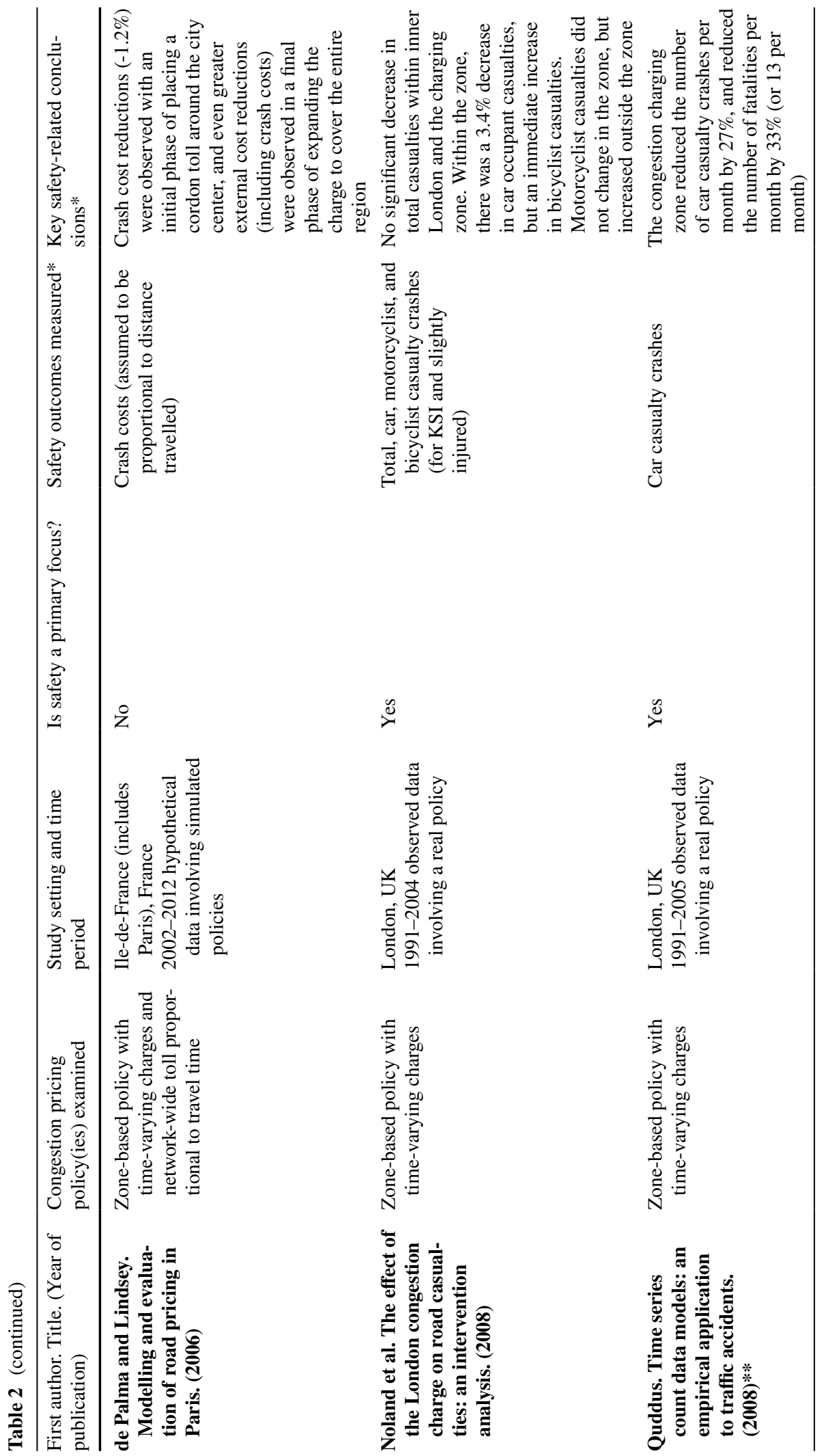




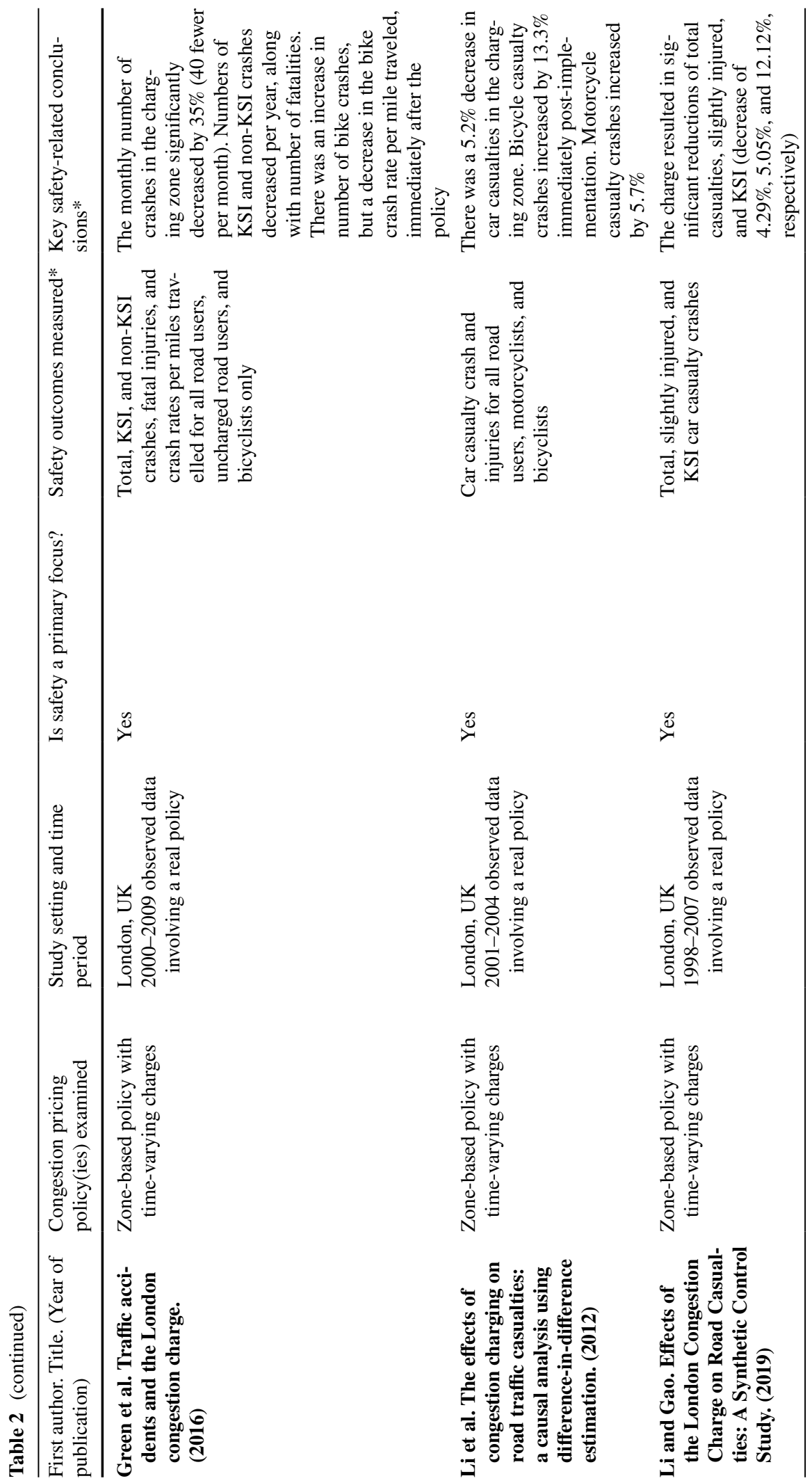




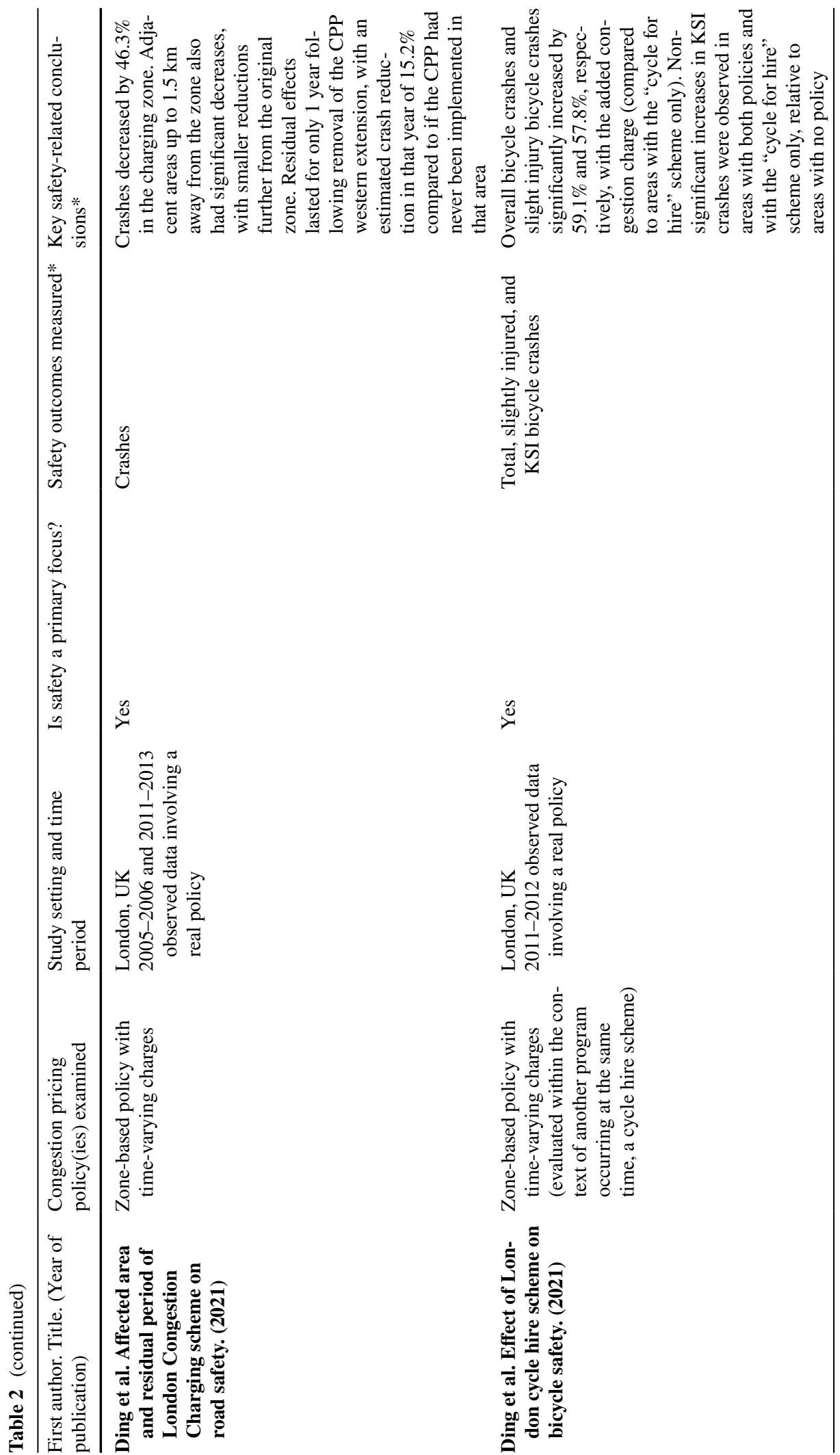




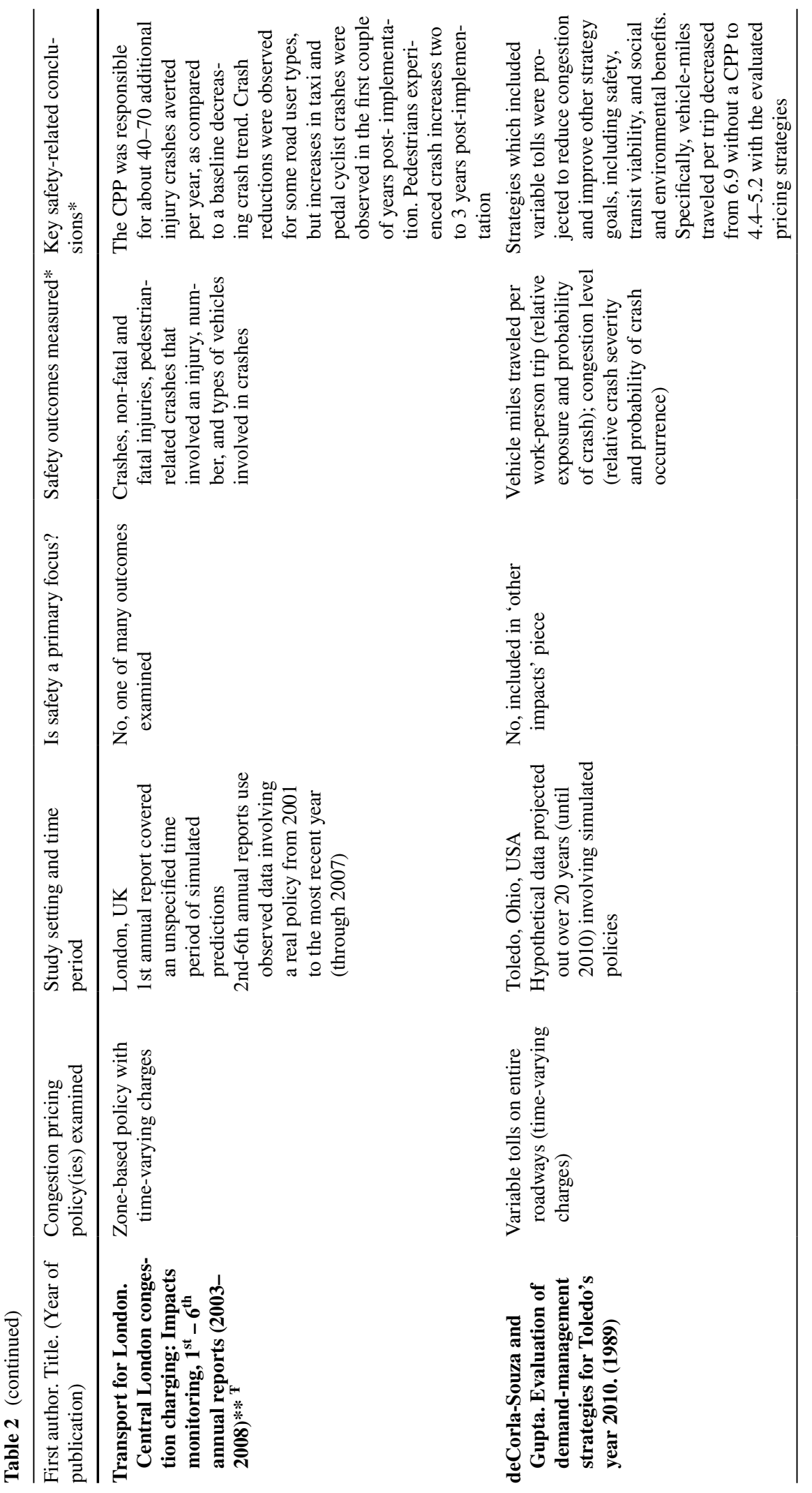




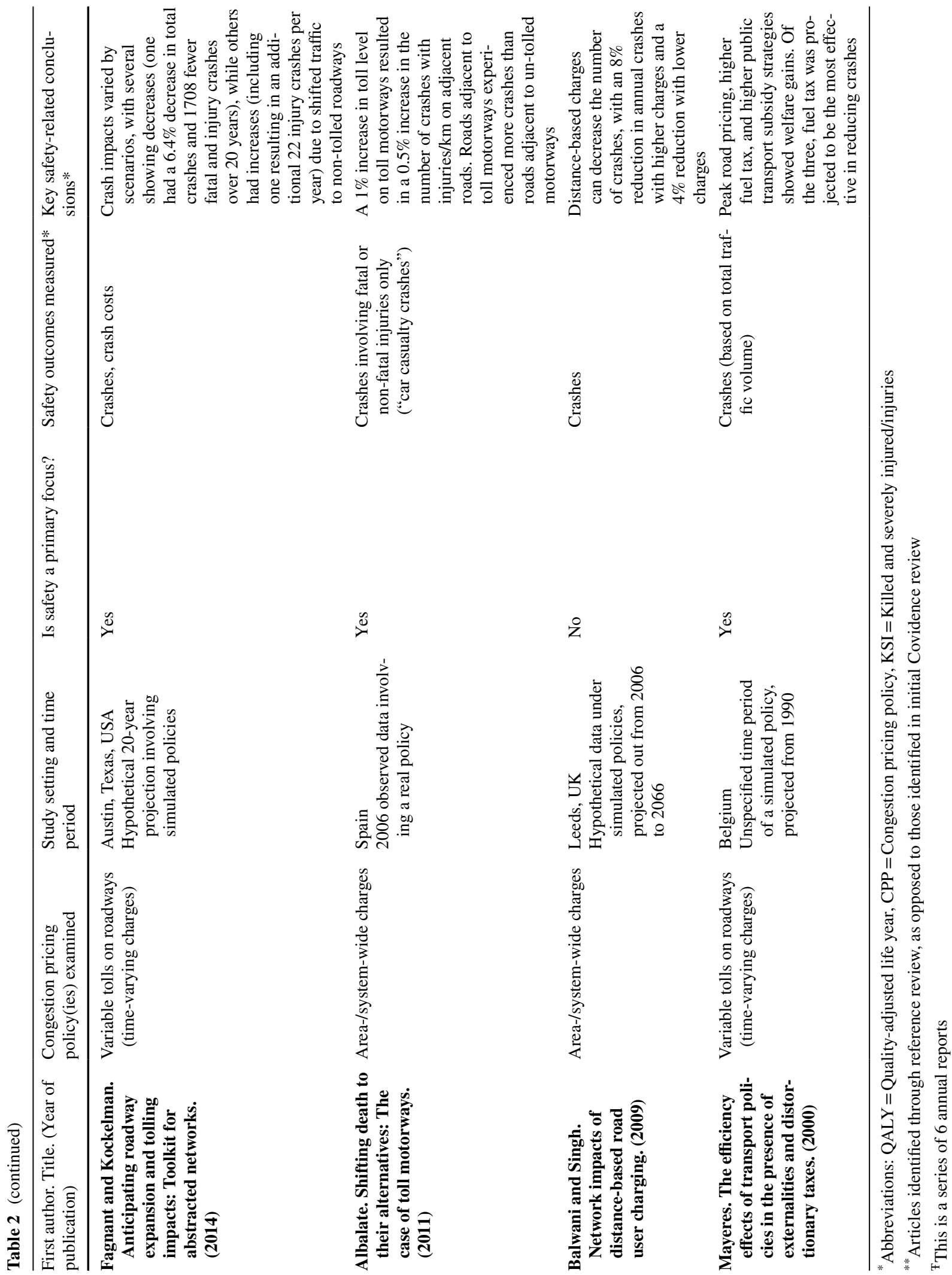


changes caused by the zone-based charging scheme were ultimately responsible for the reduction of 40-70 additional injury crashes per year beyond the crash reductions that were expected to occur as the result of all road safety initiatives and a general declining trend in road traffic crashes [36].

Other studies $(n=2)$ revealed observed and simulated increases in traffic-related harms as a result of CPP implementation. For example, one study evaluating an area-wide CPP in Spain documented increases in observed injury crashes, as a result of traffic patterns shifting to non-tolled areas [40]. Similarly, a simulated study of variable tolls in the USA indicated potential injury crash increases as a result of these shifting patterns [39].

\section{Motorcyclists}

Examinations of the London congestion charge were the only publications with results pertaining to motorcycles/powered two-wheelers. Li et al., using BoxTiao intervention analysis methods, estimated a 5.7\% increase in total motorcycle casualties (injuries of any severity) in the year immediately post-CPP implementation, with a $17.3 \%$ increase in the number killed or seriously injured (KSI) and a $1.8 \%$ increase in the number slightly injured [28]. In contrast, Noland et al. used a difference-in-difference estimation approach (also with different adjustment variables) and did not observe significant changes in motorcyclist casualties within the London charging zone during the same post-implementation period; however, the authors observed a slight increase in KSI and large increase in slight injuries (16\%, or 40 more casualties per month) immediately adjacent to the charging zone [25]. Findings in both studies were attributed to increases in motorcycle miles traveled following CPP implementation, quantified as a $15 \%$ increase within the charging zone by Noland et al. [25]. Furthermore, the TfL series reported that the average number of powered two-wheelers was slightly greater during post-CPP years compared to prior; however, involvement of these vehicles in crashes notably decreased with each consecutive year [33-36].

\section{Bicyclists}

Observed and estimated changes in bicycle crashes and injuries varied in magnitude and direction, particularly based on time since CPP implementation. Li et al., using a difference-in-difference approach with control cities, observed an increase of $13.3 \%$ in bicycle injuries resulting from crashes during the year immediately following London CPP implementation-consistent with findings by Noland et al. and Green et al. (using a Box and Tiao intervention approach and a difference-in-difference with synthetic control approach, respectively) [25, 27, 28]. Green et al. then observed an overall decrease several years after implementation in London. [27] In contrast, the TfL series, which compared numbers from similar periods across multiple years (e.g., Mar-Nov 2001 versus Mar-Nov 2004), observed decreases in bicycle crash involvement in the 2 years after London CPP implementation, followed by an increase in the third year bringing the number close to pre-congestion levels [33-36]. Wier et al. predicted an increase in vehicle-bicyclist injury collisions when simulating data up to 10 years post-CPP implementation in San Francisco [21]. However, this study also concluded that this increase would be less than the predicted increase without CPP implementation (i.e., 15 additional bicyclist injuries per year with CPP vs. 20 without CPP) [21]. Further, increases in bicyclist injuries also were observed when the CPP was assessed in conjunction with other road user strategies. Specifically, an examination of a "cycle for hire" scheme in London (launched to promote cycling as an alternative transport mode) found that regions with both this scheme and a CPP, compared to regions without the CPP, had significantly greater numbers of overall and slight injury bicycle crashes-which authors stated may have been due to CPP-related shifts from vehicle use to alternative modes such as bicycles and walking [31]. Although they examined CPP implementation in different cities and examined different types of data (observed vs. simulated), the publications by Green et al., Wier et al., and Ding et al. all attributed observed increases in the number of bicyclist injuries due to mode shifts and increases in bicycle use [21, 27, 31]. Specifically, following initial implementation of the London congestion charge, TfL estimated that bicycle flow increased with each year, and Green et al. observed a $66 \%$ increase in bike-miles traveled in the 6 years after initial implementation in London [27, 33-37]. 


\section{Pedestrians}

Similar to their 10-year predictions of bicyclist injuries, Wier et al. estimated from their partially simulated study that the number of vehicle-pedestrian injury collisions per year would remain the same (even with increased pedestrian traffic) if a CPP were implemented and that there would be a $10 \%$ increase in the count of pedestrian injuries if a CPP were not implemented [21]. The authors attributed the findings to assumptions of reduced vehicle-miles traveled under a CPP scheme while also acknowledging the model did not account for speed or other factors that could increase collision risk. The TfL series observed no significant change in the proportion of crashes affecting pedestrians (compared to vehicle occupants/ riders) in the year immediately following implementation but then observed slight increases in this proportion in years two and three post-implementation [33-36]. Authors of both publications suggested these findings may be due to increased pedestrian activity and/or shifts in transportation mode (e.g., reduced vehicle activity) [21, 33].

\section{Taxis and large vehicles (e.g., buses, trucks)}

When estimating changes in the absolute numbers of taxi and bus/coach involvement in crashes following CPP implementation, the TfL series first observed an increase in the first year and a decrease in the second year. In the third year after CPP implementation, results varied as the number of taxis involved in crashes increased, while bus/coach involvement decreased. It is important to note, however, that taxis constituted a greater proportion of all vehicles entering the congestion zone during charging hours post-implementation compared to pre-implementation, while bus proportions remained somewhat stable. Finally, the TfL series observed that the number of goods vehicles (e.g., trucks) involved in crashes consistently decreased with each year postCPP [33-36]. Green et al. assessed taxis and buses as part of a group of uncharged vehicles (including bicycles and motorcycles) under the London CPP and determined that while there was an increase in distance travelled by these vehicles, the number of crashes involving uncharged vehicles decreased by $12 \%$ [27]. Authors suggested this finding may reflect the decreased number of charged vehicles on the road, which therefore reduced the odds of uncharged vehicle involvement in crashes.

\section{Discussion}

Traffic congestion places an increasingly significant burden on commuter travel time, expenses, quality of life, air quality, productivity, and regional economies $[2,3]$. CPPs are widely recognized as a potential solution for these problems. While the impacts of such policies on congestion, emissions, revenue generation, and public acceptability have been explored [5, 7, 13-15, 43], we found a relatively sparse body of literature evaluating CPP impacts on road user safety. This review explored the findings of 18 publications with original analyses of CPP impacts on safety-related outcomes.

Publications varied between use of observed data and simulated data, safety outcomes assessed, specific policies examined, and analysis methods and approaches. The dearth of studies and range of specific policies, outcomes examined, and context creates challenges for drawing firm conclusions about policy impacts. A large proportion of studies in this review were about the London congestion charge, which was first established in 2003 and then modified and expanded in later years. Findings from London-based studies suggested that CPPs can provide some positive impacts on road user safety. However, some modes of transportation experienced initial decreases in safety immediately following CPP implementation (e.g., bicycles, motorcycles), likely due to mode shifts and increased exposure and possibly due to changing traffic flow/speeds as well. Many of these effects reversed and then improved, resulting in fewer injuries by three years postimplementation. An exception to this was pedestrian injuries, which experienced increases two to three years post-implementation. Further research is needed to examine the generalizability of London congestion charge (a zone-based CPP) findings to other contexts, particularly to other types of CPPs, and to examine longer follow-up periods to determine if impacts level-off or continue to change. 
Methodologic considerations

There were several types of study designs and analysis approaches used across included publications (e.g., difference-in-differences analysis, synthetic control study design). Pre- vs. post-CPP implementation-based studies were most common, particularly among the publications analyzing the London congestion charge. Pre vs. post studies without an "unexposed" comparison group can run the risk of producing effect estimates that are biased by timevarying confounding (e.g., changes in secular trends). Examples of studies that used specific analytic features that reduced the potential for bias include those by Percoco and Noland et al., who used time series approaches designed to reduce bias from trend and seasonal effects, and Li et al., who used a differencein-difference model to reduce bias due to regional differences [22, 25, 28]. Future research should consider potential biases, such as these, in study design and analysis approach selection. Second, the safety outcomes evaluated varied and were not always clearly defined, making comparisons across studies difficult. For example, studies that included crash counts as an outcome did not always clearly specify if their counts included crashes with motorist injuries only, or also cyclist, pedestrian, and other road user injuries. Further research and synthesis could benefit from explicit outcome definitions. Additionally, some studies measured indirect safety outcomes, such as changes in quality-adjusted life years, crash costs, and congestion levels [6, 24, 38, 42]. Although these studies provide valuable insight into safety implications of CPPs, it was not feasible to make comparisons across study findings in this review as these measures did not appear across multiple studies. Third, simulationbased studies, which can help examine the specific mechanisms that lead to CPP-related outcomes, come with their own specific considerations, primarily related to model assumptions. Among studies assessing short-term outcomes, assumptions included that changes in traffic were due to introduction of CPPs alone and that effects observed in the analyses would remain consistent several years post-implementation [23]. Studies measuring indirect effects included assumptions of proportionality-for example, that crash rates are directly proportional to vehicle-miles travelled and congestion levels [24, 38]. Most publications using simulated data explicitly acknowledged an inverse relationship between congestion levels and vehicle speeds $[6,21,24,32,38,41,42]$; however, few considered the complex relationships between these two parameters and crash occurrence or injury severity $[6,21,32,38,39]$. Additional simulation studies that incorporate these complex relationships and others, drawing on systems science models such as agent-based models and system dynamics simulation models, are warranted, as they could help test and account for this complexity.

\section{Policy and equity considerations for future CPP implementation}

There are several safety-related considerations that warrant attention in future CPP research, discussion, and implementation. Equity is a rarely mentioned but necessary consideration when evaluating CPP impacts, particularly safety impacts. CPPs have the greatest impact on two groups of individuals: regular commuters and residents of charging zones (where applicable). Travelers who are able to more easily afford charges can maintain their previous travel routes, while others may be forced to make alternate plans. This may include taking a longer route, where the saved congestion charges are offset by the costs associated with additional fuel use, vehicle wear, and lost time, or switching to another mode of transportation, such as public transit or bicycling. The latter option may have the additional consequence of increased risk of injury. For example, several publications in this review attributed post-CPP increases in bicyclist collisions to shifts in travel modes and a sudden influx of new bicyclists on roadways [21, 27, 31]. Further, spatial equity concerns arise as individuals who live and work in different places would be impacted differently by congestion charges from those who live and work in the same area [44]. Rerouting may also increase congestion in other areas that are less empowered to reduce traffic flow and consequently cause changes in the number of vulnerable road users injured/killed in those areas, with a potential disproportional impact on less empowered minorities. In addition to changing travel modes, congestion pricing often provides a new revenue stream for local governments. Options for using this revenue include decreasing income taxes (particularly for lower income individuals); reinvesting in pedestrian, bicyclist, or public transit infrastructure; or providing 
subsidies for using alternate routes [43, 45, 46]. Some of these options may help reduce inequities created by congestion pricing and have the additional benefit of increasing public acceptability for these policiesthe extent and direction of these inequity impacts should be measured prior to policy implementation. Finally, although safety is not the primary purpose behind implementation of a CPP, it is the primary goal of other transportation-related initiatives such as Vision Zero and Safe Systems [47], which have become a significant goal in cities/regions around the world in recent years. Therefore, appropriate consideration should be given to how CPPs can fit within these frameworks and provide a safe environment for all road users, along with a clear understanding of potential changes in travel behaviors, revenue generation and reinvestment, and social and safety inequities that may result from policy implementation.

Strengths and limitations

This review had several notable strengths and limitations. First, search criteria were run through multiple databases with different target audiences, so a wide net was cast for identifying eligible publications. Although search terms and criteria varied slightly because of the different structures of these databases, we anticipate no significant impact on our final results as all identified publications were thoroughly screened for final inclusion in this review by two authors. Agreement by both authors was required at all screening stages to ensure eligibility and reduce potential bias. Second, this review included reports, as they may provide an insight different from what is presented in peer-reviewed literature. This review was also not formally restricted by dates in an effort to understand the extent of safety-related CPP literature; however, we were restricted to when databases were first created. Publications required at least an abstract or summary in English, which may have eliminated some international literature. Given that congestion pricing is a strategy used around the world, this review may be missing important conclusions from international congestion pricing studies and strategies. Third, conclusions about safety impacts may not be generalizable given the wide range of CPP types and contexts (e.g., geographic location), methods used, and the significant variation in data sources and types of measured outcomes. For example, although the multiple publications focusing on the London congestion charge suggest significant benefits may be realized after CPP implementation for some road users, these findings may only apply to cities with similar infrastructure, demographic distributions, and type of CPP implemented. Further, the policies discussed in this review often included different combinations of policy exemptions and variation in other structural components (e.g., time-varying tolls, exemption of certain vehicle types); however, there is insufficient evidence for determining what specifically is leading to the observed differences in safety impacts. Future research, particularly simulation studies, can help disentangle the mechanisms that may be involved in generating positive safety outcomes, helping to identify CPP components critical for improving road user safety. Finally, safety is only one of the many aspects of health, so an additional, more extensive review of the literature is required to understand health implications of CPPs on a broader scale. However, by specifically examining "safety" on an international scale, this review comprehensively expands on a rarely explored aspect of CPP impacts, which is critical as more cities/regions consider road safety strategies such as Vision Zero.

\section{Conclusions}

CPPs have been developed to address increased traffic congestion, particularly in urban centers, and have been studied widely in the literature. These policies have been implemented in cities around the world, including London, Milan, and Stockholm. The findings of this review suggest that there are potential safety benefits for some road users following CPP implementation. However, benefits may vary by road user type and according to length of time post-implementation. The relative paucity of research specifically exploring the safety outcomes of these policies, along with the wide breadth of CPP types, implementation contexts, outcomes measured, and relationships modeled, indicates a need for additional research. Before implementing CPPs, cities/regions should consider, within the context of their own community, potential mode shifts and safety-related supports for such mode shifts, equity concerns, appropriate revenue reinvestment, and benefits in both short- and long-term time frames. 
Acknowledgements This project was supported by the Collaborative Sciences Center for Road Safety (www.roads afety.unc.edu), a United States Department of Transportation National UniversityTransportation Center (award \# 69A3551747113). Co-authors also received support from the UNC Injury Prevention Research Center, which is supported by an award (R49/CE0042479) from the Centers for Disease Control and Prevention. The funders did not play a role in the study design, collection of articles, analysis, interpretation of data, writing of the report, or in the decision to submit the article for publication.

\section{References}

1. US Department of Transportation, Federal Highway Administration. Table VM-1.Accessed February 19, 2021. https://www.fhwa.dot.gov/policyinformation/statistics.cfm

2. Schrank D, Eisele B, Lomax T. Urban Mobility Report. Texas A\&M Transportation Institute. 2019;2019:50.

3. DeCorla-Souza P. Congestion Pricing - A Primer: Overview. US Department of Transportation, Federal Highway Administration. 2008:20. Accessed December 26, 2020. https://ops.fhwa.dot.gov/publications/fhwahop08039/cp_ prim1_00.htm

4. Federal Highway Administration. Congestion Pricing Strategies.Congestion Pricing. Published March 2, 2020. https://ops.fhwa.dot.gov/congestionpricing/strategies/ index.htm. Accessed 19 Feb 2021.

5. Liu Q, Lucas K, Marsden G. Public acceptability of congestion charging in Beijing, China: how transferrable are Western ideas of public acceptability? Int J Sustain Transp. 2020;15(2):97-110. https://doi.org/10.1080/ 15568318.2019.1695158.

6. Yu W, Suh D, Song S, Jiao B, Zhang L, Muennig P. The cost-effectiveness of competing congestion pricing plans in New York city. J Transp Health. 2019;14:100586. https://doi.org/10.1016/j.jth.2019.100586.

7. Selmoune A, Cheng Q, Wang L, Liu Z. Influencing factors in congestion pricing acceptability: a literature review. J Adv Transp. 2020;2020:e4242964. https://doi. org/10.1155/2020/4242964.

8. Kaddoura I, Nagel K. Congestion pricing in a real-world oriented agent-based simulation context. Res Transp Econ. 2019;74:40-51. https://doi.org/10.1016/j.retrec.2019.01.002.

9. Hensher DA, Li Z. Referendum voting in road pricing reform: a review of the evidence. Transp Policy. 2013;25:186-97. https://doi.org/10.1016/j.tranpol.2012.11.012.

10. E Cipriani L Mannini B Montemarani M Nigro M Petrelli. Congestion pricing policies: design and assessment for the city of Rome Italy. Transp Policy. 2019;80:127-35 https:// doi.org/10.1016/j.tranpol.2018.10.004

11 M Börjesson, I Kristoffersson. The Gothenburg congestion charge. Effects, design and politics. Transp Res Part Policy Pract. 2015;75:134-46 https://doi.org/10.1016/j. tra.2015.03.011

12. Y Li, Y Guo J, Lu S Peeta. Impacts of congestion pricing and reward strategies on automobile travelers' morning commute mode shift decisions. Transp Res Part Policy Pract. 2019;125:72-88. https://doi.org/10. 1016/j.tra.2019.05.008

13. Cavallaro F, Giaretta F, Nocera S. The potential of road pricing schemes to reduce carbon emissions. Transp Policy. 2018;67:85-92. https://doi.org/10.1016/j.tranpol. 2017.03.006.

14. Chen D, Ignatius J, Sun D, Goh M, Zhan S. Impact of congestion pricing schemes on emissions and temporal shift of freight transport. Transp Res Part E Logist Transp Rev. 2018;118:77-105. https://doi.org/10.1016/j.tre.2018. 07.006.

15. Burt M, Sowell G, Crawford J, Carlson T. Synthesis of Congestion Pricing-Related Environmental Impact Analyses - Final Report. United States. Federal Highway Administration, ed. 2010;(FHWA-HOP-11-008). https:// rosap.ntl.bts.gov/view/dot/42201. Accessed 31 Aug 2021

16. Pei X, Wong SC, Sze NN. The roles of exposure and speed in road safety analysis. Accid Anal Prev. 2012;48:464-71. https://doi.org/10.1016/j.aap.2012.03.005.

17. National Center for Statistics and Analysis.Overview of Motor Vehicle Crashes in 2019. National Highway Traffic Safety Administration; 2020. Accessed May 3, 2021. https://crashstats.nhtsa.dot.gov/Api/Public/ViewPublic ation/813060

18. Insurance Institute for Highway Safety, Highway Loss Data Institute. Fatality Facts 2019: Yearly snapshot. IIHSHLDI crash testing and highway safety. Published March 2021. Accessed May 6, 2021. https://www.iihs.org/topics/ fatality-statistics/detail/yearly-snapshot

19. National Center for Statistics and Analysis. Early Estimate of Motor Vehicle Traffic Fatalitites for the First Half (JanJun) of 2020. National Highway Traffic Safety Administration; 2020. Accessed May 6, 2021. https://crashstats. nhtsa.dot.gov/Api/Public/ViewPublication/813004

20. Office of Behavioral Safety Research. Update to Special Reports on Traffic Safety During the COVID-19 Public Health Emergency: Third Quarter Data. National Highway Traffic Safety Administration; 2021:10.

21. Wier M, Bhatia R, McLaughlin J, et al. Health Effects of Road Pricing. In San Francisco Department of Public Health, San Francisco, CA. 2011.

22. Percoco M. The impact of road pricing on accidents: a note on Milan. Lett Spat Resour Sci. 2016;9(3):343-52.

23. Eliasson J. A cost-benefit analysis of the Stockholm congestion charging system. Transp Res Part Policy Pract. 2009;43(4):468-80. https://doi.org/10.1016/j.tra.2008.11. 014.

24. de Palma A, Lindsey R. Modelling and evaluation of road pricing in Paris. Transp Policy. 2006;13(2):115-26. https://doi.org/10.1016/j.tranpol.2005.11.013.

25. Noland RB, Quddus MA, Ochieng WY. The effect of the London congestion charge on road casualties: an intervention analysis. Transportation. 2008;35(1):73-91. https:// doi.org/10.1007/s11116-007-9133-9.

26. Quddus MA. Time series count data models: an empirical application to traffic accidents. Accid Anal Prev. 2008;40(5):173241. https://doi.org/10.1016/j.aap.2008.06.011.

27. Green CP, Heywood JS, Navarro M. Traffic accidents and the London congestion charge. J Public Econ. 
2016;133:11-22. https://doi.org/10.1016/j.jpubeco.2015. 10.005 .

28. Li H, Graham DJ, Majumdar A. The effects of congestion charging on road traffic casualties: a causal analysis using difference-in-difference estimation. Accid Anal Prev. 2012;49:366-77. https://doi.org/10.1016/j.aap.2012.02.013.

29. Li H, Gao L. Effects of the London Congestion Charge on Road Casualties: A Synthetic Control Study. Published online July 2, 2019:3488-3499. https://doi.org/10.1061/ 9780784482292.302

30. Ding H, Sze NN, Li H, Guo Y. Affected area and residual period of London Congestion Charging scheme on road safety. Transp Policy. 2021;100:120-8. https://doi.org/10. 1016/j.tranpol.2020.10.012.

31. Ding H, Sze NN, Li H, Guo Y. Effect of London cycle hire scheme on bicycle safety. Travel Behav Soc. 2021;22:22735. https://doi.org/10.1016/j.tbs.2020.10.002.

32. Transport for London. Central London Congestion Charging Impacts Monitoring: First Annual Report. 2003

33. Transport for London. Central London Congestion Charging Impacts Monitoring: Second Annual Report. 2004

34. Transport for London. Central London Congestion Charging Impacts Monitoring: Third Annual Report. 2005

35. Transport for London. Central London Congestion Charging Impacts Monitoring: Fourth Annual Report. 2006

36. Transport for London. Central London Congestion Charging Impacts Monitoring: Fifth Annual Report. 2007

37. Transport for London. Central London Congestion Charging Impacts Monitoring: Sixth Annual Report. 2008

38. deCorla-Souza P, Gupta JD. Evaluation of demand-management strategies for toledo's year 2010 transportation plan. Transp Res Rec. 1989;1209:1-15.

39. Fagnant D, Kockelman KM. Anticipating roadway expansion and tolling impacts: Toolkit for abstracted networks.
J Urban Plan Dev. 2014;140(4). https://doi.org/10.1061/ (ASCE)UP.1943-5444.0000188

40. Albalate D. Shifting Death to Their Alternatives: the Case of Toll Motorways. J Transp Econ Policy. 2011;45(3):457-79.

41. Balwani A, Singh S. Network impacts of distance-based road user charging. NETNOMICS Econ Res Electron Netw. 2009;10(1):53-75. https://doi.org/10.1007/s11066-008-9025-y.

42. Mayeres I. The Efficiency Effects of Transport Policies in the Presence of Externalities and Distortionary Taxes. $J$ Transp Econ Policy. 2000;34(2):233-59.

43. Anas A. The cost of congestion and the benefits of congestion pricing: a general equilibrium analysis. Transp Res Part B Methodol. 2020;136:110-37. https://doi.org/10. 1016/j.trb.2020.03.003.

44. Yang H, Zhang X. Multiclass network toll design problem with social and spatial equity constraints. J Transp Eng. 2002;128(5):420-8. https://doi.org/10.1061/(ASCE)0733947X(2002)128:5(420).

45. Guo X, Yang H. Pareto-improving congestion pricing and revenue refunding with multiple user classes. Transp Res Part B Methodol. 2010; 44(8):972-82. https://doi.org/10. 1016/j.trb.2009.12.009.

46. Adler JL, Cetin M. A direct redistribution model of congestion pricing. Transp Res Part B Methodol. 2001;35(5):44760. https://doi.org/10.1016/S0191-2615(00)00003-5.

47. Finkel E, McCormick C, Mitman M, Abel S, Clark J. Integrating the Safe System Approach with the Highway Safety Improvement Program: An Informational Report. Federal Highway Administratssion. 2020:59

Publisher's Note Springer Nature remains neutral with regard to jurisdictional claims in published maps and institutional affiliations. 